\title{
A dimensão ética da competência em informação sob a perspectiva da Filosofia
}

\section{Eliane Pellegrini}

Doutoranda do Programa de Pós-Graduação em Ciência da Informação da Universidade Federal de Santa Catarina (UFSC). Mestre em Ciência da Informação, Bacharel em Biblioteconomia (UFSC)

Elizete Vieira Vitorino

\begin{abstract}
Pós-doutora pela Faculdade de Letras (FLUP), da Universidade do Porto (UP), Portugal. Doutora em Engenharia de Produção (2004) na área de Mídia e Conhecimento e Educação a Distância (EaD).Mestre em Engenharia de Produção (1996) na área de Gestão da Qualidade em Bibliotecas, ambas titulações conferidas pela Universidade Federal de Santa Catarina (UFSC)
\end{abstract}

http://dx.doi.org/10.1590/1981-5344/2953

Este trabalho aborda a dimensão ética da competência em informação sob uma perspectiva filosófica. Buscamos caracterizar esta dimensão a partir dos fundamentos da filosofia da informação e da ética da informação. Partimos do pressuposto de que, na atual sociedade, há uma associação importante entre a filosofia, a ética e a competência em informação. A pesquisa é de caráter exploratória e bibliográfica. Observamos que a dimensão ética da competência em informação relaciona-se com saber dosar a informação e equilibrar valores conflitantes, de forma que os resultados das ações do indivíduo no ambiente profissional estejam voltados para a justiça e o bem coletivo. Isso exige do bibliotecário reflexão sobre a ação. Definir critérios para o uso ético e legal da informação ou seguir critérios pré-existentes (leis, resoluções, normalizações) também é uma característica desta dimensão. Consideramos que esta é uma dimensão que se manifesta, principalmente, em situações informacionais que envolvam um problema, um conflito de valores, um posicionamento e/ou uma tomada de decisão.

Palavras-chave: Competência em informação. Dimensão ética. 


\title{
The ethical dimension of information literacy under the perspective of Philosophy
}

\begin{abstract}
This paper addresses the ethical dimension of information literacy in a philosophical perspective. We seek to characterize this dimension from the fundamentals of the philosophy of information and information ethics. We assume that, in today's society, there's a significant association between philosophy, ethics and information literacy. The research is exploratory and bibliographical character. We note that the ethical dimension of information literacy relates to know how to dispense the information and balance conflicting values, so that the results of the actions of the individual in the workplace are facing justice and collective good. This requires the librarian reflection on the action. Set criteria for ethical and legal use of information or follow pre-existing criteria (laws, resolutions, normalization) is also a feature of this size. We consider that this is a dimension which is manifested primarily in information situations involving a problem, a conflict of values, positioning and / or decision making.
\end{abstract}

Keywords: Information competence. Information literacy. Ethical dimension.

Recebido em 06.10.2016 Aceito em 07.05.2018

\section{Introdução}

A competência em informação envolve habilidades em definir, localizar e acessar informações, atitudes e valores. Ela pode ser compreendida no fazer do bibliotecário a partir de quatro dimensões: técnica, estética, política e ética (VITORINO; PIANTOLA, 2011). Em uma perspectiva filosófica, a dimensão técnica está na capacidade de lidar com os conteúdos - conceitos, comportamentos e atitudes - e à habilidade de construí-los e reconstruí-los. A dimensão estética diz respeito à presença da sensibilidade e sua orientação numa perspectiva criadora. A dimensão política relaciona-se à participação na construção coletiva da sociedade e ao exercício de direitos e deveres. $\mathrm{E}$, a dimensão ética diz respeito à orientação da ação, fundada no princípio do respeito e da solidariedade, na direção da realização de um bem coletivo (RIOS, 2010). A dimensão ética, conforme Rios (2010, p. 108), é a "dimensão fundante da 
competência, porque a técnica, a estética e a política ganharão significado pleno quando, além de se apoiarem em fundamentos próprios de sua natureza, se guiarem por princípios éticos". Portanto, estas dimensões se complementam e ganham sentido na competência em informação. Entretanto, a compartimentalização permite o estudo aprofundado de cada dimensão.

Este trabalho procura caracterizar a dimensão ética da competência em informação a partir da literatura das áreas de filosofia da informação e da ética da informação. E, sob esta perspectiva, é possível indagar: quais conceitos da filosofia da informação e da ética da informação podem ser úteis à compreensão da dimensão ética da competência em informação?

A ética, neste estudo, diz respeito diretamente à experiência cotidiana dos indivíduos, levando-nos a uma reflexão sobre os valores adotados, os atos praticados e a maneira pela qual decisões são tomadas. Trata-se da "face da filosofia que se debruça sobre os valores que orientam nossas ações e relações na sociedade" (RIOS, 2008, p. 80). Consequentemente, a medida que a sociedade se transforma, surgem novas formas de pensar os problemas básicos apresentados pelas relações entre os homens. Segundo Sánchez Vázquez (2013), existe uma estreita vinculação entre os conceitos morais e a realidade humana, social, sujeita historicamente à mudança.

A análise da dita "sociedade da informação", contexto no qual surgiram as preocupações dos estudiosos quanto à competência em informação, nos reporta ao uso intensivo de informação, mas também ao excesso de informação e aos desafios que se apresentam aos indivíduos nesse contexto.

Os fundamentos da ética estão em crise no mundo, de acordo com Morin (2005). Pare este filósofo, trata-se de uma crise de religação, uma vez que, "o ato moral é um ato de religação: com o outro, com uma comunidade, com uma sociedade e, no limite, religação com a espécie humana" (MORIN, 2005, p. 29). A configuração da sociedade contemporânea demanda, portanto, uma reflexão sobre os aspectos éticos relacionados à informação, uma vez que as relações entre os indivíduos redefinem novos padrões culturais, políticos e éticos.

No que se refere a dimensão ética da competência em informação, acreditamos que fundamentos de áreas surgidas na sociedade contemporânea podem contribuir para a caracterização dessa dimensão. A filosofia da informação pode contribuir para entender a natureza da informação e do problema ético que a envolve. A ética da informação, por sua vez, nos permite compreender o desenvolvimento das relações morais no campo informativo.

A fim de identificar os fundamentos básicos destas áreas, nos propomos a realizar uma pesquisa exploratória e bibliográfica. A pesquisa exploratória visa criar familiaridade em relação a um fato ou fenômeno por meio da prospecção de materiais que possam informar ao pesquisador a real importância do problema, o estágio em que se encontram as informações já disponíveis a respeito do assunto e revelar ao pesquisador novas fontes de informação (SANTOS, 2000). Na pesquisa bibliográfica 
levanta-se o conhecimento disponível na área, identificando teorias produzidas, analisando-as e avaliando sua contribuição para auxiliar na compreensão do problema objeto da investigação (KÖCHE, 2008).

Para concretizar a pesquisa bibliográfica, foram localizados em bases de dados internacionais e periódicos brasileiros artigos que abordassem, principalmente, as seguintes temáticas: competência em informação, ética, filosofia da informação e ética da informação. Livros da área de Filosofia que tratam da ética e da área da Ciência da Informação sobre competência em informação também foram consultados. Os resultados são apresentados nos itens seguintes. Nos "aventuramos" em realizar conexões entre as temáticas evidenciadas nos propósitos deste trabalho e trazer uma nova perspectiva aos estudos sobre a competência em informação.

\section{A filosofia da informação e o problema ético}

A filosofia da informação, expressão introduzida pelo filósofo italiano Luciano Floridi, emerge no contexto da sociedade da informação. Seu surgimento se deu frente à inquietação e aos problemas acarretados pela grande quantidade de informação gerada, manipulada, armazenada e distribuída por meio das tecnologias. O fenômeno da informação "mudou o mundo profunda, irreversível e problematicamente, a um ritmo e com um âmbito nunca antes experimentados", segundo Floridi (2003 apud ILHARCO, 2003, p. 23).

Historicamente, a filosofia da informação nasceu da filosofia da computação, que delineia o seu objeto na informação tecnológica e nos instrumentos informacionais em questão (ILHARCO, 2003). A vasta presença das tecnologias de informação e comunicação (TIC) na sociedade contemporânea é um fenômeno permanente que vem se constituindo no modo, meio e contexto da ação dos homens no mundo. À medida que as novas tecnologias penetram horizontalmente os mais variados domínios da experiência humana, o fenômeno da informação vem ganhando relevância crescente na sociedade contemporânea (ILHARCO, 2003).

Embora a informação e a sua comunicação sejam fenômenos básicos da sociedade humana, Capurro e Hjorland (2007) esclarecem que é o surgimento das tecnologias da informação e comunicação (TIC) e seus impactos globais que caracterizam a sociedade da informação.

Questionar o que é informação neste contexto, de acordo com Ilharco (2003), é algo semelhante a questionar o que é o homem ou o que é o conhecimento. Trata-se de uma questão primordial, entretanto, "nunca, nem sobre a informação, sobre o homem ou no que se refere ao conhecimento, existirão noções ou definições universais e consensualmente aceitas" (ILHARCO, 2003, p. 43). Crnkovic e Hofkirchner (2011) observam que o conceito de informação é poderoso e evasivo, uma vez que pode ser associado à diversas explanações, dependendo dos requisitos e intenções. 
Capurro e Hjorland (2007) analisam o termo "informação" como conceito interdisciplinar. Eles revisam as contribuições de teóricos das áreas de Física, Biologia, Sistemas de Informação, Filosofia, Psicologia, Sociologia, Biblioteconomia, Documentação e Ciência da informação, entre outras, ao longo dos séculos XX e XXI, para a formação do conceito de informação no sentido de conhecimento comunicado. Estes autores identificaram que existem muitos conceitos de informação e eles estão inseridos em estruturas teóricas mais ou menos explícitas. O conceito de informação aparece em domínios diferentes e é fluido, uma vez que sua natureza muda conforme a finalidade e contexto.

Com base em outros teóricos, Crnkovic e Hofkirchner (2011) também admitem que a informação pode ser entendida sob uma gama de possibilidades: ela pode ser dinâmica; pode ser transmitida, recebida e processada, ou pode ser produzida, construída; pode ser objetiva ou subjetiva; pode ser vista como coisa, como propriedade ou como relação; pode ser interpretada a partir da perspectiva de teorias formais ou de teorias informais; e, pode ser vista como sintática, como semântica ou como fenômeno pragmático.

Os conceitos, portanto, são expressos na linguagem de alguma teoria. Capurro e Hjorland (2007, p. 160) observam que "quase toda disciplina científica usa o conceito de informação dentro do seu próprio contexto e com relação a fenômenos específicos".

A Ciência da Informação, comumente, utiliza o conceito de informação no sentido de conhecimento comunicado, como se pode observar nos estudos de Le Coadic (2004) e Robredo (2007). Informação, para Le Coadic (2004, p. 4), "é um conhecimento inscrito (registrado) em forma escrita (impressa ou digital), oral ou audiovisual, em um suporte". Robredo (2007, p. 60) complementa essa definição afirmando que a informação...

[...] pode ser registrada, duplicada, transmitida, armazenada, organizada, processada, recuperada, mas somente quando extraída da mente e codificada, pela linguagem natural (fala ou escrita), seguindo normas e padrões (gramatica, sintaxe) próprios de cada língua, ou de outras linguagens criadas pelo homem (linguagens de programação, que também têm suas gramáticas e sintaxes).

Há um processo de transformação do conhecimento na mente, e em informação fora da mente. Assim, informação é o conhecimento externalizado, mediante algum tipo de codificação, conforme defende Robredo (2007), deixando clara a utilização do conceito de informação no sentido de conhecimento comunicado.

A informação, de certa forma, sempre foi pressuposta como óbvia, transparente, igual para todos os que a acessam em qualquer ocasião, observa Ilharco (2003). Contudo, uma vez questionado esse pressuposto, em uma sociedade caracterizada pela geração constante de nova e de mais informação, a transparência desaparece.

Nesse sentido, a filosofia da informação é um campo de estudos destinado a responder à questão "qual é a natureza da informação", 
buscando, deste modo, demonstrar sua legitimidade (FRANCELIN; PELLEGATTI, 2004).

Esse campo de estudos é definido por Floridi (2002, p. 137, tradução nossa) como

um campo filosófico preocupado com a investigação crítica, de natureza conceitual e princípios básicos de informação, incluindo sua dinâmica, utilização e ciências, e a elaboração e aplicação da informação teorética (theoretic) e metodologias computacionais para a resolução de problemas filosóficos.

A filosofia da informação, conforme Ilharco (2003), evolui a partir e em função de um único fenômeno fundador - a informação -, e, nesta perspectiva, há um conjunto de problemas sobre os quais esta filosofia debruça-se ou deverá debruçar-se no futuro. O conjunto de problemas apresentado por Ilharco (2003) pode ser visualizado na Figura 1.

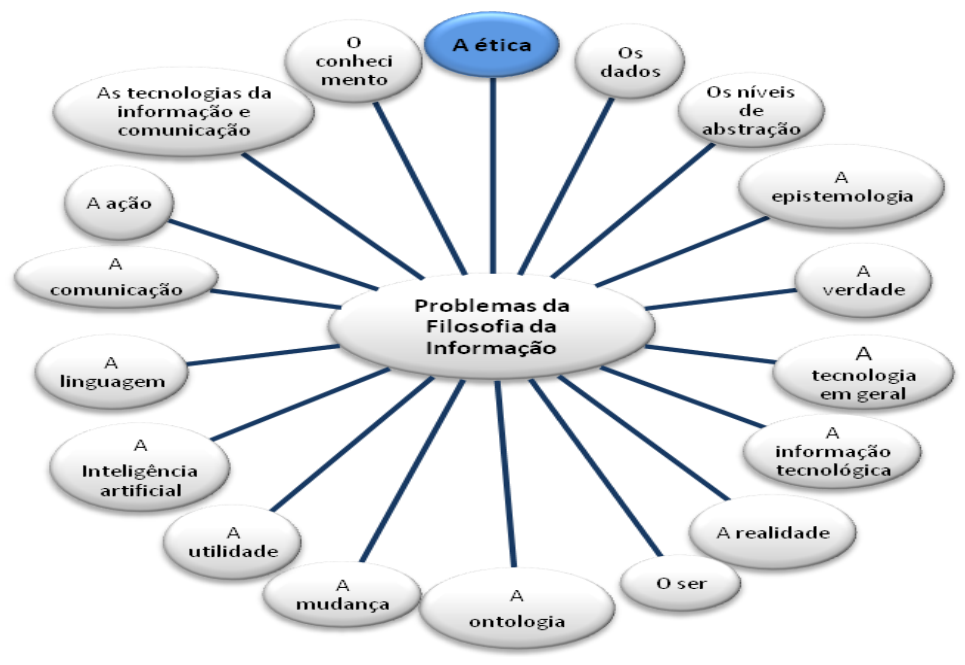

Figura 1 - Problemas da filosofia da informação Fonte: Dados da pesquisa.

Dentre os problemas da filosofia da informação, destacamos o problema ético. Este refere-se, conforme Ilharco (2003), às mudanças de comportamentos, de estruturas, de valores, de estratégias e de poderes provocados, desencadeados ou relacionados com a disseminação das TIC pelo planeta, que anunciam novos desafios e problemas à humanidade. Ao abrirem novas possibilidades de atuação e oportunidades, as tecnologias também possibilitam o surgimento de ameaças $e$ a 
progressão de comportamentos e de práticas fortemente questionáveis em termos éticos e morais. Tratam-se de questões que se relacionam com a dignidade do ser humano, com o respeito dos direitos dos profissionais, com o respeito pela privacidade da vida pessoal de cada um, com a responsabilidade social, com a solidariedade, com a partilha de valores entre os indivíduos, entre outros aspectos. Os avanços da ciência e da tecnologia, nomeadamente desenvolvimentos na genética e na biotecnologia, têm de igual modo apresentado novos desafios éticos. A filosofia da informação também reflete e analisa estes tipos de questões, procurando na ética fundamental e na ontologia, respostas capazes de enquadrar ética e moralmente estes novos cenários.

Dentre os problemas adjacentes ao fenômeno da informação, estão as questões voltadas para o uso informacional e as implicações éticas deste uso. Entende-se, portanto, que os fundamentos da filosofia da informação servem de base para esta pesquisa, uma vez que, este campo se desenvolveu em decorrência dos problemas criados pelas tecnologias de informação e comunicação e pelo excesso de informações, assim como, a competência em informação, que se volta para o uso da informação pelo indivíduo.

Portanto, compreender a competência em informação e sua dimensão ética exige considerar os pilares desta sociedade e o problema ético mencionado por Ilharco (2003), que se refere a questões éticas em torno do uso da informação.

$\mathrm{Na}$ próxima seção, apresentamos questões éticas relacionadas à informação por meio dos fundamentos da ética da informação.

\section{A ética da informação: evolução e reflexões teóricas}

O conceito de ética da informação ou ética informacional, como preferem alguns autores, destacou-se nos últimos anos do século $X X$, devido ao impacto das TIC que permitem a produção, armazenamento, processamento e divulgação de informações de forma global, democrática e interativa (FERNÁNDEZ-MOLINA, 2009). Entretanto, sua origem se deu na Grécia antiga com o conceito de parrhesia" - que significa "falar sobre qualquer coisa" -, diretamente relacionado à liberdade de expressão (CAPURRO, 2006).

A evolução da ética da informação, nos Estados Unidos (EUA), está relacionada, primeiramente, à Biblioteconomia e, em seguida, à Computação. Os primeiros estudiosos a utilizarem a expressão foram Robert Hauptman, que escreveu diversas obras e artigos tratando de questões éticas, cujo livro mais conhecido, publicado em 1989, se intitula Ethical challenges in librarianship, e Rafael Capurro que escreveu um artigo, em 1988, intitulado Informationethos und Informationsethik. No entanto, algumas das questões de ética da informação já haviam sido

\footnotetext{
${ }^{1}$ Parrhesia refere-se a um compromisso público pessoal com a crença da verdade. O conhecimento do crente está ligado ao seu ser. Trata-se da verdade sobre o seu próprio ser. "Dizer a verdade" torna-se um imperativo moral, sob condições específicas. O sujeito está ciente do que deveria ser, bem como dos riscos para si próprio no caso de negar publicamente um estado de coisas, em nome de possíveis alternativas que ele acredita serem melhores (CAPURRO, 2006).
} 
levantadas em 1980 por Barbara J. Kostrewski e Charles Oppenheim (FROEHLICH, 2004).

A ética da informação surge num momento em que o questionamento teórico da moral é cada vez mais urgente, devido ao impacto das TIC na sociedade. Os conflitos que antes eram locais, agora transformam-se em conflitos globais e vice-versa. A ética é um sinal que as normas e hierarquias de valores que eram consideradas certas estão, na atual sociedade, em crise (CAPURRO, 2010).

Buscamos, portanto, entender a informação sob a perspectiva da sua ética. A ética da informação, na concepção de Capurro (2010), é uma ética intercultural da informação, que permite um relacionamento entre as normas morais universais e as tradições morais locais. A reflexão ética, segundo este autor, transita entre pólos de universalização e a efetivação em situações particulares. Capurro (2010) considera a ética uma teoria descritiva e emancipatória sob perspectivas históricas e sistemáticas. Como teoria descritiva, analisa as distintas estruturas e relações de poder que determinam a atividade informativa em distintas culturas e épocas. Como teoria emancipatória, se ocupa da crítica ao processo de relações morais no campo da informação e compreende aspectos individuais, coletivos e universais.

Em outras palavras, Capurro (2010) explica que a ética da informação observa o desenvolvimento das relações morais no campo informativo e em especial no campo da rede digital, expõe e critica mitos informativos e analisa relações de poder que determinam o campo em questão, expõe contradições ocultas de práticas de poder, e, observa o desenvolvimento de concepções teóricas no campo da informação.

A ética da informação na concepção de Floridi (1999; 2006; 2010), por sua vez, pode ser vista como a evolução de uma ética ambiental, cuja principal função é (ou deveria ser) o bem-estar da infoesfera. Seu princípio fundamental é algo mais elementar que a vida, o Ser entendido informacionalmente e, portanto, algo mais fundamental que prazer ou dor, ou seja, a entropia² (FLORIDI, 2010).

A infoesfera, para Floridi (1999, p. 44, tradução nossa), "é o ambiente constituído pela totalidade de entes informacionais - incluindo todos os agentes - processos, suas propriedade e relações mútuas". Entes informacionais referem-se a "qualquer coisa que possa ou venha a existir, como as gerações futuras; e tudo o que era, mas não é mais, como nossos ancestrais ou civilizações antigas" (FLORIDI, 2006, p. 26, tradução nossa).

A questão ética levantada pela Ética da Informação, conforme Floridi (2010, p. 46), é

[...] o que é bom para uma entidade informacional e para a infoesfera em geral? A resposta é dada por uma teoria minimalista de desertos: qualquer entidade informacional é reconhecida como estando no centro de preocupação ética que merece reconhecimento

\footnotetext{
2 Entropia, neste contexto, refere-se a qualquer tipo de destruição, corrupção, poluição e esgotamento de objetos informacionais, ou seja, qualquer forma de empobrecimento do Ser (FLORIDI, 2006).
} 
e deveria ajudar a regular a implementação de qualquer processo informacional que o envolve, se possível.

A investigação de uma ética da informação tem como tarefa, de acordo com González de Gómez (2010, p. 157), "indagar as possíveis distorções comunicativo-informacionais que afetam tanto a realização de metas de uma vida boa, como de justiça social, a partir de nossas comunidades e de sua inserção nas formas globais da cultura, da economia e da política".

Neste sentido, Capurro (2010) trata de algumas práticas e ações de informação que implicam em critérios éticos e morais na sociedade da informação. Para este autor, o questionamento do ethos comunicacional e informacional, ou seja, das normas, princípios e valores que fundamentam a comunicação da informação em uma determinada sociedade, gira em torno de temas variados como: a privacidade da propriedade intelectual; o acesso livre ao conhecimento; o direito à expressão nas redes digitais; a censura; novas definições de gênero; a identidade digital; as comunidades digitais; o plágio; a sobrecarga informacional; a exclusão digital; e, o controle social.

Algumas questões problemáticas que envolvem a ética também são evidenciadas no discurso de González de Gómez (2010, p. 157):

[...] ao mesmo tempo em que as tecnologias digitais oferecem possibilidades inúmeras de desenvolvimento econômico e social, enquanto as inovações tecnológicas ficarem sujeitas ao predomínio dos mecanismos de mercado e de formas de valorização capitalista, a produção, circulação e apropriação de informações ignoraria as metas do bem estar social e da justiça social. Questões referentes à confidencialidade, privacidade, propriedade intelectual, segurança, censura, movimentos de código aberto, liberdade de expressão, referem-se a procedimentos seletivos de informação e desinformação e à operação de mecanismos exteriorizados de regulamentação e de controle acerca da geração, circulação e acesso/uso de informação.

Na perspectiva de Capurro (2009), os novos problemas éticos têm a ver, em primeiro lugar, com o não acesso à rede digital por aqueles que não possuem condições financeiras e, principalmente, com a educação necessária para utilizar e tirar proveito das suas potencialidades. $E$, em segundo lugar, a rede digital desempenha um papel cada vez mais importante na vida política, de modo que a ética deve levantar questões e fazer estudos empíricos, assim como desenvolver novos conceitos e teorias sobre as oportunidades de participação do cidadão por meio da rede.

O acesso ao conhecimento é citado por Capurro (2009) e Freire, Isa Maria (2010) como um tema ético importante nesta sociedade. Capurro (2009) destaca, neste sentido, a questão dos direitos autorais ou de propriedade intelectual em geral, incluindo todos os tipos de criações artísticas e tudo que envolve patentes. Outra questão importante é o acesso equitativo ao conhecimento, particularmente em instituições de 
ensino público (escolas, faculdades, universidades, centros públicos de pesquisa), especialmente se parte da produção do conhecimento científico é financiada pelo Estado. A questão central diz respeito à proteção da vida privada dos cidadãos que está relacionada com a responsabilidade do Estado no campo da segurança pública. Freire, Isa Maria (2010, p. 80), por sua vez, levanta a questão da "diferenciação entre os que têm e os que não têm acesso à Internet". Segundo esta autora, o advento das novas tecnologias da informação acrescentou uma nova forma de desigualdade e exclusão social às já existentes: a exclusão digital.

Sob um outro enfoque, Preisig, Rösch e Stückelberger (2014) tratam dos dilemas éticos que aparecem, por vezes, porque os valores éticos entram em conflito entre si. Alguns exemplos disso são: o acesso irrestrito à informação não é compatível com a privacidade e proteção de dados; liberdade ilimitada de expressão entra em conflito com proteção contra difamação; proteção dos menores requer restrição de acesso informação o que leva a uma violação do tratamento igualitário. Essas questões demonstram a necessidade de equilibrar valores conflitantes.

Ressaltamos que outros períodos da história não estiveram ausentes de questões relacionadas à ética da informação. Liberdade de expressão, acesso à informação, igualdade de tratamento, entre outras, foram questões importantes no passado e ainda são valores vulneráveis (PREISIG; RÖSCH; STÜCKELBERGER, 2014). Entretanto, de acordo com Capurro (2009), as questões éticas levantadas pela mídia de massa antes da Internet eram mais fáceis de solucionar, uma vez que bastava colocar regras de controle adequadas nas emissoras de transmissão e fornecer uma educação ética adequada para os intermediários responsáveis pela seleção e/ou interpretação de mensagens, ou seja, os jornalistas. No momento em que a rede digital global surgiu, aumentaram as dificuldades para resolver problemas que antes podiam ser parcialmente solucionados com um sistema de regulação local, já que atualmente, qualquer receptor pode ser um emissor.

Nesta perspectiva, o olhar ético da informação envolve a questão da definição de critérios para o seu uso considerando os hábitos culturais e, nesse plano, estão também as investigações acerca de que tipo de informação deve ou não ser colocada em ambientes informacionais estruturados digitalmente, e quais as consequências dessas ações (BEMBEM; SANTOS, 2014).

As soluções dos problemas éticos informacionais da sociedade são consideradas complexas por Freire, Gustavo (2010). O autor chama a atenção para a necessidade de

[...] formar sujeitos não apenas para assimilar ou consumir informação, mas também para produzi-la e saber bem usá-la. Por isso, uma ética da informação deve significar uma ética para a informação. Ou seja, trata-se de formar (moralmente) o agente ou o sujeito da informação (FREIRE, GUSTAVO, 2010, p. 8).

Capurro (2009) ressalta que saber dosar a informação e a comunicação requer um longo aprendizado que deveria começar na 
família e na escola. Não se pode esquecer dessa habilidade também no mundo do trabalho, sob pena de criar uma situação de saturação digital que muitas vezes culmina em enfermidades mentais e/ou corporais.

Em concordância com o pensamento destes autores, Marti e VegaAlmeida (2005) afirmam que a competência em informação aparece como o processo que permite responder aos desafios contemporâneos éticos, políticos e legais: a info divisão e o capitalismo informacional; a propriedade intelectual e a economia da informação; a liberdade de expressão; os delitos informativos e as tradições morais; o acesso universal; e, o controle da rede.

Encerrando essas breves reflexões, observamos que no caso de uma ética da informação para a sociedade contemporânea, não há um padrão de procedimentos a ser consultado e seguido. O desenvolvimento das TIC, iniciado no final do século $X X$, veio acompanhado de benefícios para a sociedade, mas também de problemas éticos relacionados ao uso da informação. Assim, há que se refletir sobre os aspectos éticos relacionados à informação e seu uso. Neste trabalho, buscamos relacionar tais aspectos com a competência em informação, considerando o fundamento da ética da informação que se volta para o bem estar da sociedade e considera as diferenças nas tradições morais e culturais.

\section{A dimensão ética da competência em informação}

A dimensão ética "começa quando entra em cena outros. Qualquer lei, por moral ou jurídica que seja, regula sempre relações interpessoais, incluindo as que se estabelecem com quem a impõe" (ECO; MARTINI, 1999, p. 45). A ética, para Sung e Silva (2011, p. 41) é "uma dimensão que permite o questionamento sobre as práticas, atitudes, regras e ações humanas", considerando-se as consequências dessas práticas, atitudes, regras e ações para outros.

A dimensão ética da competência profissional é uma racionalização do comportamento humano, na visão de Artigas e Tóbon (2006). As práticas, atitudes, regras e ações do indivíduo no ambiente de trabalho geram consequências que devem estar voltadas para a justiça e o bem coletivo.

Nesse sentido, a ética, ao estar presente na ação do indivíduo, no âmbito pessoal e profissional, considera as implicações das ações na coletividade. Evidenciamos a presença da dimensão ética em diversas definições da competência em informação (CATTS; LAU, 2008; ABELL et al., 2004), numa perspectiva voltada, predominantemente, para o uso eficaz e ético da informação.

Catts e Lau (2008) definem a competência em informação como as habilidades de reconhecer necessidades de informação, localizar e avaliar a qualidade das informações, armazenar e recuperar informações, fazer uso eficaz e ético da informação, e, aplicar informações para criar e comunicar conhecimento.

$\mathrm{Na}$ visão de Abell et al. (2004), a competência em informação compreende, entre outras habilidades, a de saber definir necessidades 
informacionais, saber encontrar e avaliar a informação, utilizar e comunicar a informação de forma ética. Compreender a ética e seu uso responsável no que se refere à competência em informação, segundo Abell et al. (2004), implica em saber porque a informação deve ser usada de forma responsável, respeitar a confidencialidade e sempre reconhecer o trabalho dos outros indivíduos, compreender a sua natureza e usos para informar corretamente e de forma imparcial. Salienta-se, neste sentido, que bibliotecários possuem o papel de atestar a veracidade dos dados e informações disponibilizados, pois conhecem as fontes de informação.

No documento Towards Information Literacy Indicators, Catts e Lau (2008) destacam que os padrões de competência em informação existentes (por exemplo os estabelecidos pela American Library Association em 2005), incluem princípios éticos voltados para o uso da informação. No âmbito educacional, uma das preocupações que envolve o uso ético da informação é a questão do plágio. Segundo estes autores, pesquisas demonstram que quanto mais cresce o acesso à internet nos países, maior é a incidência de plágio, e defendem que o ensino voltado para o uso ético da informação - criação, distribuição e uso da informação - reduz essa incidência.

Em um estudo sobre os aspectos éticos e legais da competência em informação e a formação dos bibliotecários, Mata e Casarin (2011) abordam questões relacionadas à propriedade intelectual, copyright, direito autoral e plágio. Segundo estas autoras, o conhecimento das leis de direitos autorais nacionais e internacionais, que contempla as condições de uso de obras, e o conhecimento da normalização, que no Brasil segue os padrões da Associação Brasileira de Normas Técnicas (ABNT), é importante para os bibliotecários. A normalização dos documentos influencia na recuperação de informação e está relacionada à questão ética, uma vez que ao citar corretamente um documento atribuise os créditos devidos ao(s) autor(es), direitos autorais, propriedade intelectual, plágio e ao copyright. Mata e Casarin (2011, p. 130) defendem que "somente tendo estes conhecimentos e atitudes éticas, o bibliotecário possui condições de ensinar outras pessoas a respeitarem os aspectos que envolvem o uso legal da informação".

Percebemos, portanto, que a dimensão ética da competência em informação está diretamente ligada ao uso ético e eficaz da informação e que ao profissional da informação cabe fazer esse "uso ético", para assim, promovê-lo no âmbito profissional aos usuários da informação. Para que o uso se dê de forma responsável, ao bibliotecário cabe conhecer as leis e normas que regem seu uso legal. Entretanto, há outros aspectos intrínsecos a esta dimensão.

Menezes e Vitorino (2014) identificam que a dimensão ética da competência em informação refere-se ao uso responsável da informação, mas também ao bem coletivo, ao bem comum e à cidadania. Seu objetivo é a realização de boas atitudes. Esta dimensão é vital para efetivar a competência, uma vez as outras dimensões - técnica, estética, política ganharão significado pleno quando, além de se apoiarem em fundamentos 
próprios de sua natureza, se guiarem pelos seguintes princípios éticos: o respeito, a justiça, a solidariedade (RIOS, 2010).

Sobre estes princípios éticos, Rios (2011) esclarece que o respeito é o princípio nuclear da ética, uma vez que dele decorrem os outros. Respeitar implica reconhecer a presença do outro como igual, em sua humanidade. Para respeitar alguém é preciso que se reconheça sua existência, antes de mais nada. Justiça é a igualdade na diferença. Existem diferenças de gênero, de idade, de cor, de religião etc., mas todos os indivíduos são iguais em direitos. A solidariedade, por sua vez, se firma na consideração do outro para além dos deveres, das prescrições. Nela se evidencia a disponibilidade para partilhar efetivamente a existência, na pluralidade de valores (RIOS, 2011).

Considerando os princípios éticos citados por Rios (2011), Farias e Vitorino (2009, p. 8) observam que a dimensão ética da competência em informação "se relaciona à orientação da ação, baseada nos princípios de respeito e da solidariedade, do convívio e da realização de um bem coletivo". O bem do homem, segundo Aristóteles (2001, p. 27) é "a atividade da alma em consonância com a virtude e, se há mais de uma virtude, em consonância com a melhor e mais completa entre elas".

Os valores são metas boas, valiosas que constituem o Bem da pessoa e da sociedade, e as virtudes são ações boas, aptas a realizar aquelas metas. Um valor é uma meta que o homem julgue valiosa, individualmente ou coletivamente, com vistas à consecução de um interesse pessoal ou social. Em Ética a Nicómaco, de Aristóteles (2001), o valor máximo é a felicidade, que se alcança mediante ações excelentes, chamadas virtudes. A liberdade também é considerada um valor maior (MARCHIONNI, 2004).

A virtude requer equilíbrio e excelência. A excelência da ação consiste na prática do "justo meio" entre dois extremos, dessa forma, a virtude da coragem, por exemplo, é o meio justo entre a temeridade e a covardia (MARCHIONNI, 2004). Marchionni (2004, p. 47) defende que "toda ação humana pode ser virtuosa ou não, na medida em que é executada de maneira excelente e ajuda a alcançar um valor".

Se toda ação pode ser virtuosa ou não, o eixo central da reflexão ética relaciona-se, de acordo com Rios (2011), à ideia de responsabilidade, que está articulada com a de liberdade e à noção de compromisso - esse compromisso traz a marca da moral. No compromisso o indivíduo empenha a sua palavra, criadora de valores, de significações.

Em um estudo voltado para a atuação do bibliotecário no campo educacional, Farias e Vitorino (2009) observam que a dimensão ética da competência do bibliotecário refere-se a um trabalho de qualidade que se executa como deve ser, entendido como múltiplas significações relativas ao bem comum. A realização do bem comum é sinônimo de felicidade.

Com base nas reflexões dos autores mencionados sobre a dimensão ética da competência em informação, percebemos que esta refere-se ao uso legal e responsável da informação, fundamentado nas leis e normas que regem o uso da informação em cada país, e nos princípios éticos de 
respeito, justiça, solidariedade e compromisso, que resultam no bem coletivo e na cidadania. Esta dimensão exige um caráter crítico e um julgamento de valor por parte do bibliotecário - que é um profissional da informação. Diante das situações que se apresentam à profissão, é recorrente tomar posições e assumir posturas no ambiente de trabalho, principalmente, com relação ao uso da informação.

\section{Considerações finais}

A partir da análise dos fundamentos das áreas de filosofia da informação e ética da informação, observamos que a dimensão ética da competência em informação diz respeito à ação humana, com base em princípios para a orientação da boa conduta dos indivíduos, em um contexto repleto de dilemas e distorções comunicativo-informacionais que afetam a realização de metas para uma vida boa.

Nesta perspectiva, a dimensão ética da competência em informação relaciona-se diretamente com saber dosar a informação e a comunicação e, ao mesmo tempo, equilibrar valores conflitantes, de forma que os resultados das ações do indivíduo no ambiente profissional estejam voltados para a justiça e o bem coletivo. Isso exige do bibliotecário reflexão sobre a ação.

Definir critérios para o uso ético e legal da informação ou seguir critérios pré-existentes (leis, resoluções, normalizações) também é uma característica desta dimensão. Deste modo, consideramos que esta é uma dimensão que se manifesta, principalmente, em situações informacionais que envolvam um problema, um conflito de valores, um posicionamento e/ou uma tomada de decisão.

As considerações sobre a dimensão ética da competência em informação feitas até aqui são importantes para a área de Ciência da Informação pelos seguintes motivos: a caracterização desta dimensão e os elementos que a constituem podem servir de base para estudos futuros mais aprofundados sobre o uso ético e legal da informação no âmbito da atuação prática do bibliotecário; além disso, conhecer os dilemas e/ou problemas informacionais da sociedade da informação é fundamental aos cursos de graduação em Biblioteconomia para direcionar a formação do bibliotecário, de modo que este se torne competente em informação e agente desta competência.

\section{Referências}

ABELL, A. et al. Alfabetización en información: la definición de CILIP (UK). Boletín de la Asociación Andaluza de Bibliotecarios, Espanha, n. 77, p. 79-84, dez. 2004. Disponível em: <dialnet.unirioja.es/descarga/articulo/1302261.pdf>. Acesso em: 28 set. 2016.

ARISTÓTELES. Ética a Nicômaco. São Paulo: Martin Claret, 2001. (A obra-prima de cada autor).

ARTIGAS, C. M. T.; TOBÓN, S. T. (Coord.). El diseño del plan docente en información y documentación acorde con el espacio europeo de educación superior: un enfoque por 
competências. Madri: Universidad Complutense de Madrid, 2006. Disponível em: <http://eprints.ucm.es/6005/1/MANUAL.pdf>. Acesso em: 28 set. 2016.

BEMBEM, A. H. C.; SANTOS, P. L. da C. Ética informacional: uma abordagem no contexto da inteligência coletiva. DataGramaZero: Revista de Informação, Rio de Janeiro, v. 15, n. 4, ago. 2014. Disponível em: 〈http://www.dgz.org.br/ago14/Art_04.htm\#R1〉. Acesso em: 28 set. 2016.

CAPURRO, R. Towards an ontological foundation of information ethics. Ethics and Information Technology, [s.1], v. 8, n. 4, p. 175-186, 2006. Disponível em: <http://www.capurro.de/oxford.html>. Acesso em: 28 set. 2016.

CAPURRO, R. Ética intercultural de la información. In: GOMES, H. F.; BOTTENTUIT, A. M.; OLIVEIRA, M. O. E. de (Org.). A ética na sociedade, na área da informação e da atuação profissional: o olhar da Filosofia, da Sociologia, da Ciência da Informação e da formação e do exercício profissional do bibliotecário no Brasil. Brasília, DF: Conselho Federal de Biblioteconomia, 2009. p. 43-64. Disponível em: <http://www.cfb.org.br/popup/a_etica.pdf>. Acesso em: 28 set. 2016.

CAPURRO, R. Desafíos téoricos y prácticos de la ética intercultural de la información. In: FREIRE, G. H. de A. (Org.). Ética da informação: conceitos, abordagens, aplicações. João Pessoa: Ideia, 2010. p. 11-51 Disponível em:

<http://ru.ffyl.unam.mx:8080/bitstream/10391/1328/1/teaching\%20information\%20ethics.pdf $>$. Acesso em: 28 set. 2016.

CAPURRO, R.; HJORLAND, B. O conceito de informação. Perspectivas em Ciência da Informação, Belo Horizonte, v. 12, n. 1, p. 148-207, jan./abr. 2007. Disponível em: $<$ http://portaldeperiodicos.eci.ufmg.br/index.php/pci/article/view/54/47>. Acesso em: 28 set. 2016.

CATTS, R.; LAU, J. Towards information literacy indicators. Paris: UNESCO, 2008. Disponível em: <http://www.uis.unesco.org/Library/Documents/wp08_InfoLit_en.pdf>. Acesso em: 28 set. 2016.

CRNKOVIC, G. D.; HOFKIRCHNER, Wolfgang. Floridi's “open problems in Philosophy of Information", ten years later. Information, [s.1.], v. 2, p. 327-359, 2011. Disponível em: <http://www.mdpi.com/2078-2489/2/2/327/pdf>. Acesso em: 28 set. 2016.

ECO, H.; MARTINI, C. M. Em que creem os que não creem? São Paulo: Record, 1999.

FARIAS, C. M.; VITORINO, E. V. Competência informacional e dimensões da competência do bibliotecário no contexto escolar. Perspectivas em Ciência da Informação, Belo Horizonte, v. 14, n. 2, p. 2-16, maio/ago. 2009. Disponível em:

<http://www.scielo.br/pdf/pci/v14n2/v14n2a02.pdf>. Acesso em: 28 set. 2016.

FERNÁNDEZ-MOLINA, J. C. La información en el entorno digital: principales áreas con implicaciones éticas. In: GOMES, H. F.; BOTTENTUIT, A. M.; OLIVEIRA, M. O. E. de (Org.). A ética na sociedade, na área da informação e da atuação profissional: o olhar da Filosofia, da Sociologia, da Ciência da Informação e da formação e do exercício profissional do bibliotecário no Brasil. Brasília, DF: Conselho Federal de Biblioteconomia, 2009. p. 65-93. Disponível em: $<$ http://www.cfb.org.br/pop-up/a_etica.pdf $>$. Acesso em: 28 set. 2016.. 
FLORIDI, L. Information ethics: on the philosophical foundation of computer ethics. Ethics and Information Technology, Holanda, v. 1, p. 37-56, 1999. Disponível em: <http://link.springer.com/content/pdf/10.1023\%2FA\%3A1010018611096.pdf >. Acesso em: 28 set. 2016.

FLORIDI, L. What is the philosophy of information? Metaphilosophy, Estados Unidos da América, v. 33, n. 1/2, p. 123-145, jan. 2002. Disponível em: <http://onlinelibrary.wiley.com/doi/10.1111/1467-9973.00221/abstract>. Acesso em: 28 set. 2016.

FLORIDI, L. Information ethics, its nature and scope. ACM SIGCAS Computers and Society, Estados Unidos da América, v. 36, n. 3, set. 2006. Disponível em: $<$ http://dl.acm.org/ft_gateway.cfm?id=1195719\&type=pdf\&CFID=585979531\&CFTOKEN= 54605198>. Acesso em: 28 set. 2016.

FLORIDI, L. Biblioteconomia e Ciência da Informação (BCI) como Filosofia da Informação Aplicada: uma reavaliação. InCID: Revista de Ciência da Informação e Documentação, Ribeirão Preto, v. 1, n. 2, p. 37-47, jul./dez. 2010. Disponível em: <http://www.revistas.usp.br/incid/article/view/42318/45989>. Acesso em: 28 set. 2016.

FRANCELIN, M. M.; PELLEGATI, C. Filosofia da informação: reflexos e reflexões. Transinformação, Campinas, v. 16, n. 2, p. 123-132, maio/ago. 2004. Disponível em: <http://periodicos.puc-campinas.edu.br/seer/index.php/transinfo/article/view/716/696>. Acesso em: 28 set. 2016.

FREIRE, G. H. de A. (Org.). Ética da informação: conceitos, abordagens, aplicações. João Pessoa: Ideia, 2010. Disponível em:

<http://ru.ffyl.unam.mx:8080/bitstream/10391/1328/1/teaching\%20information\%20ethics.pdf >. Acesso em: 28 set. 2016.

FREIRE, I. M. A consciência possível para uma ética da informação na sociedade em rede. In: FREIRE, G. H. de A. (Org.). Ética da informação: conceitos, abordagens, aplicações. João Pessoa: Ideia, 2010. p. 78-105. Disponível em:

<http://ru.ffyl.unam.mx:8080/bitstream/10391/1328/1/teaching\%20information\%20ethics.pdf >. Acesso em: 28 set. 2016.

FROEHLICH, T. A brief history of information ethics. Bid: textos universitaris de biblioteconomia i documentación, Espanha, n. 13, 2004. Disponível em:

<http://bid.ub.edu/13froel2.htm>. Acesso em: 28 set. 2016.

GONZÁLEZ DE GÓMEZ, M. N. Perspectivas em ética da informação: acerca das premissas, das questões normativas e dos contextos da reflexão. In: FREIRE, G. H. de A. (Org.). Ética da informação: conceitos, abordagens, aplicações. João Pessoa: Ideia, 2010. p. 147-163. Disponível em:

<http://ru.ffyl.unam.mx:8080/bitstream/10391/1328/1/teaching\%20information\%20ethics.pdf >. Acesso em: 28 set. 2016.

ILHARCO, F. Filosofia da informação: uma introdução à informação como fundação da ação, da comunicação e da decisão. Lisboa: Universidade Católica, 2003.

KÖCHE, J. C. Fundamentos de metodologia científica: teoria da ciência e iniciação à pesquisa. Petrópolis: Vozes, 2008. 
LE COADIC, Y.-F. A ciência da informação. 2. ed. rev. e atual. Brasília: Briquet de Lemos, 2004.

MARCHIONNI, A. Ética: a arte do bom. São Paulo (SP): Pontifícia Universidade Católica, 2004.

MARTI, Y.; VEJA-ALMEIDA, R. L. Sociedad de la información: los mecanisnos reguladores en el contexto de una sociedad emergente. Ciência da Informação, Brasília, v. 34, n. 1, p. 37-44, jan./abr. 2005. Disponível em:

<http://revista.ibict.br/ciinf/index.php/ciinf/article/view/602/541>. Acesso em: 28 set. 2016.

MATA, M. L. da; CASARIN, H. de C. S. Aspectos éticos e legais da competência informacional e a formação do bibliotecário: um estudo com graduandos de Biblioteconomia da Região Sudeste. Revista EDICIC, Marília, v. 1, n. 1, p. 119-134, jan./mar. 2011.

Disponível em:

$<$ http://www.edicic.org/revista/index.php?journal=RevistaEDICIC\&page=article\&op=downlo ad\&path\%5B \%5D=13\&path\%5B\%5D=pdf > . Acesso em: 28 set. 2016.

MENEZES, P. L.; VITORINO, E. V. A competência informacional fundamentada na dimensão ética. Revista da Faculdade de Biblioteconomia e Comunicação da UFRGS, Porto Alegre, v. 20, n. 2, p. 86-107, jul./dez. 2014. Disponível em:

<http://www.seer.ufrgs.br/index.php/EmQuestao/article/view/46044/32151>. Acesso em: 28 set. 2016.

MORIN, E. O método 6: ética. 2. ed. Porto Alegre: Sulina, 2005.

PREISIG, A. V.; RÖSCH, H.; STÜCKELBERGER, C. Ethical dilemmas in the information society: how codes of ethics help to find ethical. Geneva: Globethics.net, 2014. Disponível em: <http://www.ifla.org/files/assets/faife/publications/misc/ethical-dilemmas-in-theinformation-society.pdf $>$. Acesso em: 28 set. 2016.

RIOS, T. A. A presença da filosofia e ética no contexto profissional. Organicom, São Paulo, v. 5, n. 8, p. 78-88, 1. sem. 2008. Disponível em:

<http://www.revistaorganicom.org.br/sistema/index.php/organicom/article/view/145/245>. Acesso em: 28 set. 2016.

RIOS, T. A. Compreender e ensinar: por uma docência da melhor qualidade. 8. ed. São Paulo: Cortez, 2010.

RIOS, T. A. Ética e competência. 20. ed. São Paulo: Cortez, 2011.

ROBREDO, Jaime Filosofia da ciência da informação. In: TOUTAIN, L. M. B. B. (Org.). Para entender a Ciência da Informação. Salvador: EDUFBA, 2007. p. 35-73.

SÁNCHEZ VÁZQUEZ, A. Ética. 35. ed. Rio de Janeiro: Civilização Brasileira, 2013.

SANTOS, A. R. dos. Metodologia científica: a construção do conhecimento. 3. ed. Rio de Janeiro: DP\&A Editora, 2000.

SUNG, J. M.; SILVA, J. C. Conversando sobre ética e sociedade. Petrópolis: Vozes, 2011. 
VITORINO, E. V.; PIANTOLA, D. Dimensões da competência informacional. Ciência da Informação, Brasília, v. 40, n.1, p. 99-110, jan./abr. 2011. Disponível em: $<$ http://revista.ibict.br/cienciadainformacao/index.php/ciinf/article/view/1918/1397>. Acesso em: 28 set. 2016. 